\title{
Ultrasound findings in classic metaphyseal lesions: emphasis on the metaphyseal bone collar and zone of provisional calcification
}

\author{
Megan B. Marine ${ }^{1}$, Roberta A. Hibbard ${ }^{2}$, S. Gregory Jennings ${ }^{3} \&$ Boaz Karmazyn ${ }^{1}$ \\ 1. Department of Radiology and Imaging Sciences, Riley Hospital for Children, \\ Indiana University School of Medicine, 705 Riley Hospital Drive, Room 1053, \\ Indianapolis, IN, 46202, USA
}

2. Department of Pediatrics, Riley Hospital for Children, Indiana University School of Medicine, Indianapolis, IN, USA

3. Department of Radiology and Imaging Sciences, Indiana University School of Medicine, Indianapolis, IN, USA

\begin{abstract}
\section{BACKGROUND}

The classic metaphyseal lesion (CML) is highly specific for non-accidental trauma in infants. While the radiographic findings are well documented, there is little literature on the ultrasound (US) appearance.
\end{abstract}

\section{OBJECTIVE}

To evaluate US findings in CMLs identified on radiographs.

\section{MATERIAL AND METHODS}

This institutional review board-approved, retrospective evaluation of targeted US of CMLs was performed in selected groups of children from 2014 to 2017. Only CMLs confidently identified on radiography by a consensus of two radiologists were included. US images were obtained with a linear transducer, including longitudinal images at lateral, anterior, medial and posterior aspects. Two pediatric radiologists evaluated the US appearance, specifically the metaphyseal bone collar for thickness, deformity and fracture, as well as the sonographic zone of provisional calcification for irregularity and appearance of multiple lines. Radiography was the reference standard.

\section{RESULTS}


Twenty-two patients (13 female; mean age: 4.2 months) were identified, with $39 \mathrm{CMLs}$ in the tibia $(n=22)$, femur $(n=11)$, humerus $(n=3)$, radius $(n=2)$ and fibula $(n=1)$. Thirty-three of the 39 CMLs (85\%) were identified on US, while 6 (15\%) were not seen (false negatives). Thirty of the $39(77 \%)$ had metaphyseal bone collar thickening, $29(74 \%)$ had collar deformity and $12(31 \%)$ had visible fracture of the collar. At the sonographic zone of provisional calcification, 16/39 (41\%) had irregularity and $5(13 \%)$ had multiple lines visible.

\section{CONCLUSION}

Identifying metaphyseal bone collar and zone of provisional calcification abnormalities is key to recognizing CMLs on US. While additional studies are necessary to evaluate the accuracy of US in the diagnosis of CMLs, our findings suggest US may have a potential role in either confirming or evaluating radiographically equivocal/occult CMLs.

\section{INTRODUCTION}

In evaluating a child with concern for child abuse, imaging plays a vital role. Often the fractures of child abuse are asymptomatic and not clinically suspected on physical exam alone. The skeletal survey, which includes radiographs of the entire axial and appendicular skeleton, is included in the standard evaluation of a child younger than 2 years of age in whom there is concern for child abuse [1]. There are fractures that have been found to be highly specific for child abuse, which can be diagnosed by the skeletal survey. The classic metaphyseal lesion $(C M L)$ is highly specific for non-accidental trauma in infants. These lesions are most commonly found in the long bones: distal femur, proximal and distal tibia, and proximal humerus [2,3,4,5,6]. Accurately diagnosing CMLs and distinguishing between CMLs and normal anatomical variations are crucial. Missing a specific injury can place the child back into an abusive environment and result in morbidity and mortality [7]. On the other hand, an inaccurate diagnosis may result in unnecessary emotional stress as the child may potentially be removed from the family.

Other imaging modalities, including whole-body magnetic resonance imaging (MRI) and 18F-NaF positron emission tomography (PET) imaging have shown some advantages in imaging for suspected abuse, but they have not been proven useful in evaluating these specific fractures $[8,9]$. Compared to MRI and 18F-NaF PET, ultrasound 
(US) has the advantage of having higher spatial resolution, as well as the ability to visualize cartilage and soft tissues without the need for sedation or ionizing radiation. The main drawbacks of US include operator dependency, small field of view, reflection by the bony cortex and limitation to superficial tissues.

The unique anatomy of the immature long bone, including non-ossification of the epiphysis (Fig. 1), makes US a potential imaging modality for evaluating the metaphyseal bone collar and the junction of the collar with the cortex and the curved metaphyseal bone border. The metaphyseal bone collar, a rim of bone encompassing the growth plate and in contiguity with the metaphyseal cortex $[10,11]$, is easily identified and evaluated on US (Fig. 2). The collar, thought to support the physis, normally has an appearance of a stepoff contour and/or a small spur and is demonstrated to be involved in CMLs [12,13,14]. In 1993, Markowitz et al. [15] published a pictorial paper on US of the metaphysis and demonstrated the normal sonographic anatomy of the metaphyseal bone collar and three cases of CMLs. Additionally, the US appearance of epiphyseal separation has been illustrated [11, 16], but as far as we know, there was no follow-up study on the specific imaging findings of US in children with CMLs. 


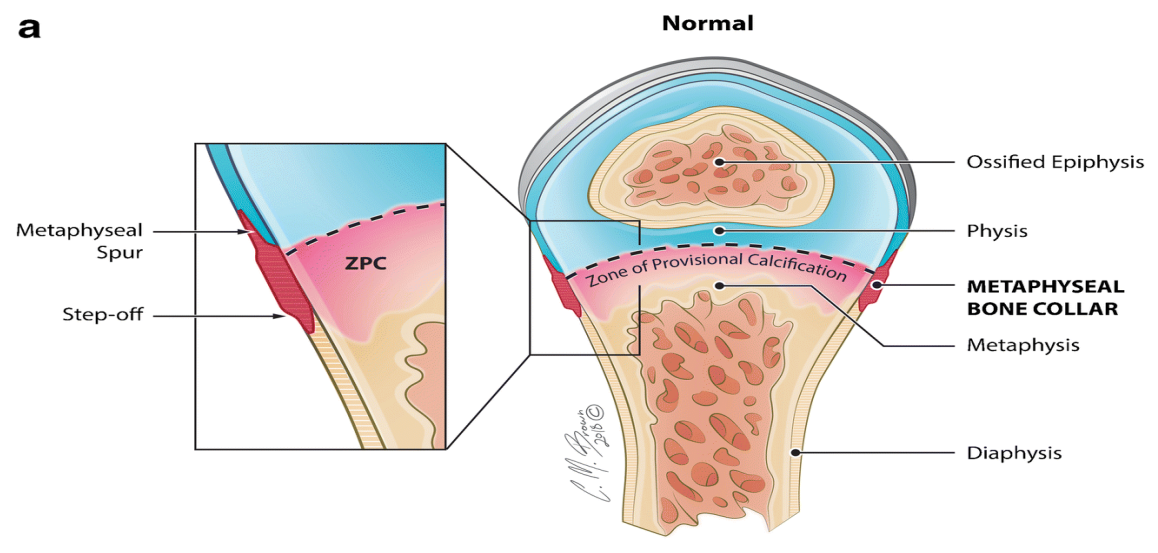

b

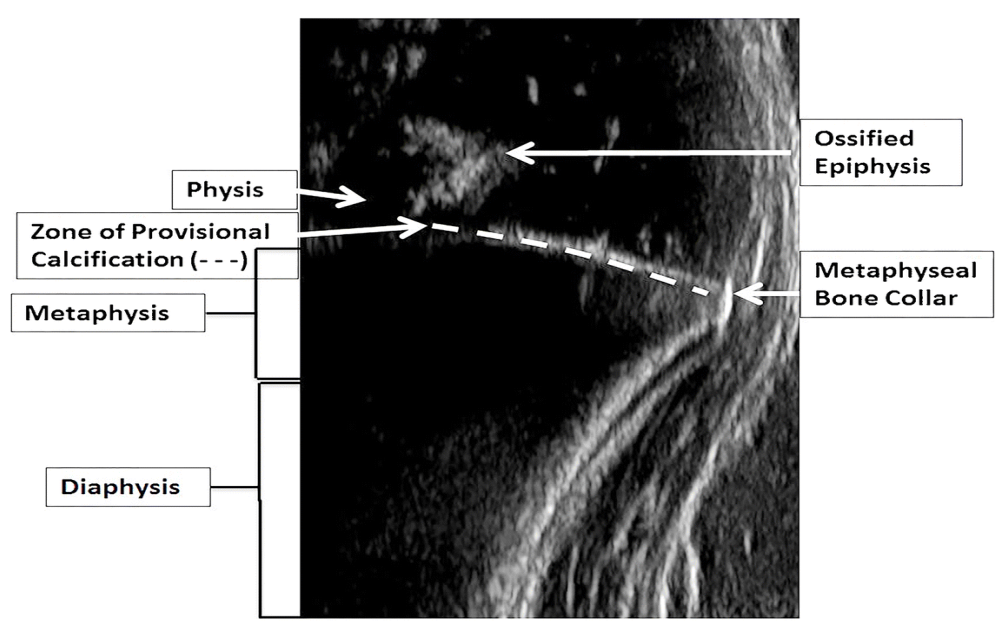

Fig 1. Anatomy of the distal immature long bone (a), demonstrating the normal metaphyseal bone collar as a rim of bone encompassing the growth plate and in contiguity with the metaphyseal cortex with the appearance of a step-off contour and/or a small spur. b Corresponding, labeled longitudinal US image of distal immature long bone 


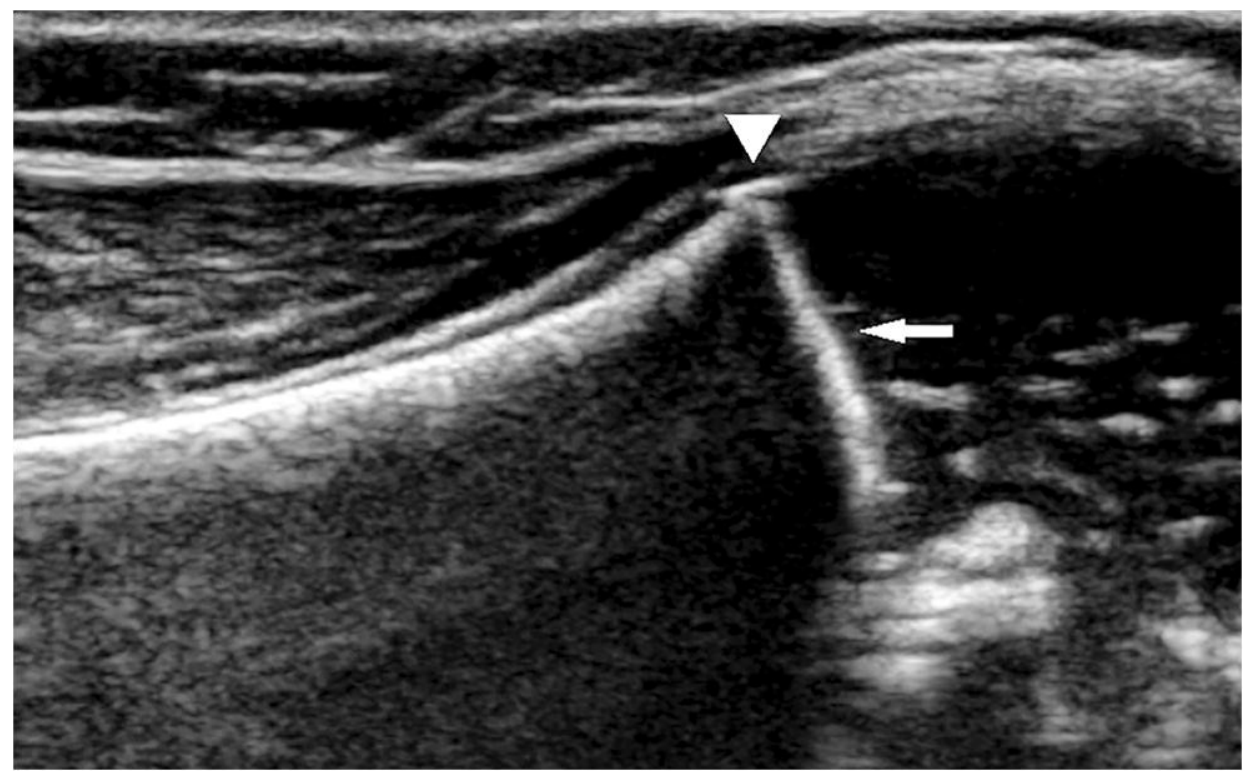

Fig 2. Normal right medial distal femur longitudinal US in a 36-day-old girl demonstrates the normal appearance of the metaphyseal bone collar (arrowhead), which is linear, hairline in thickness and intimately associated with the underlying metaphysis. The sonographic zone of provisional calcification (arrow) is a single, thin, echogenic line

The aim of our study is to analyze the US findings of known CMLs initially diagnosed by radiography.

\section{MATERIALS AND METHODS}

\section{POPULATION}

This retrospective, HIPAA-compliant study was approved by our institutional review board. Patients were recruited for the study from two groups of patients who had skeletal surveys performed for possible child abuse and subsequent US for evaluation of CMLs from 2014 to 2017 . We excluded patients with rickets. One group of patients included those for whom the original radiologist was not confident in the radiographic diagnosis of CML and requested US be performed to possibly aid in the diagnosis. A second group of patients was recruited from patients with definite CMLs on skeletal survey who then had US of the CMLs after informed consent was signed by the legal guardian. 
We included only patients with definite CMLs based on the skeletal survey radiographs, diagnosed in consensus by two fellowship-trained, American Board of Radiology Certificate of Added Qualification (CAQ) pediatric radiologists, B.K. and M.B.M., who work together in our department, with 21 and 5 years of experience, respectively.

\section{SKELETAL SURVEY TECHNIQUE}

Our skeletal survey technique follows the American College of Radiology-Society for Pediatric Radiology (ACR-SPR) guidelines, with additional views including lateral radiographs of long bones $[1,17]$.

\section{ULTRASOUND TECHNIQUE}

Focused US studies of the metaphyses were performed with either an IU22 or EPIQ 5 system (Philips Healthcare, Bothell, WA) high-resolution (5 to $17 \mathrm{MHz}$ ) linear transducer. Given the limitations of transverse imaging for anatomical reasons, only longitudinal images at the lateral, anterior, medial and posterior aspects of the metaphyses were performed by the same two fellowship-trained, CAQ pediatric radiologists (Fig. 2).

\section{ULTRASOUND ASSESSMENT}

The two pediatric radiologists evaluated the US studies in consensus. The metaphyseal bone collar was specifically evaluated. The following findings were recorded: increased thickness (subjectively greater than hairline thickness) (Fig. 3), deformity (not straight) (Fig. 3) and fracture (discontinuity of the echogenic line of the cortex) (Fig. 4). 


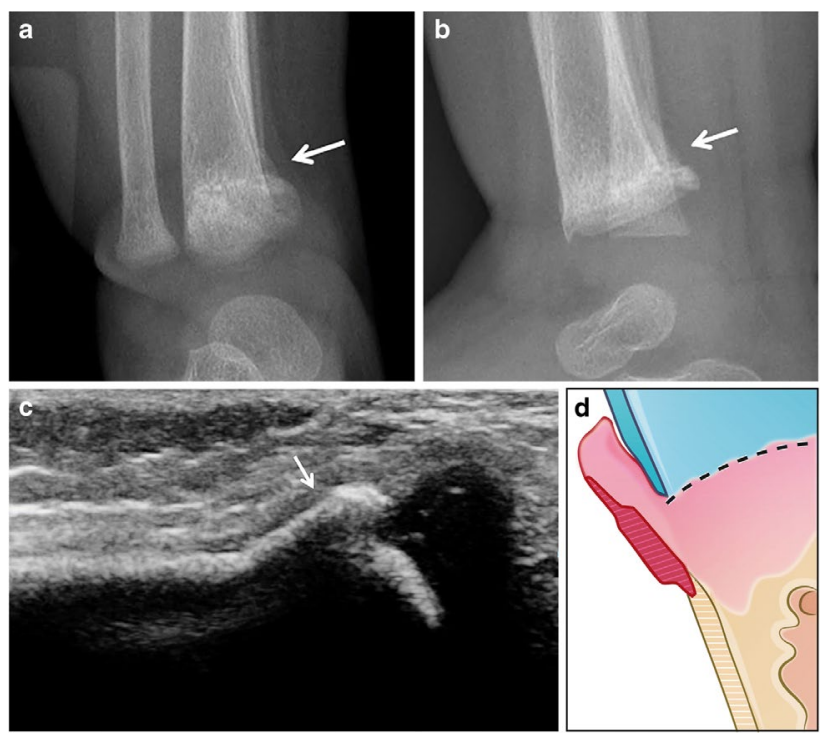

Fig. 3 Anteroposterior and lateral radiographs of a 3-month-old girl demonstrate right distal tibial metaphyseal deformity, subphyseal lucency and subperiosteal new bone formation extending to the metaphysis (arrows in a and b), consistent with healing CML. Longitudinal US image (c) of the medial distal tibia metaphysis demonstrates metaphyseal bone collar thickening and deformity (arrow), which is significantly thicker and with irregular contour. The illustration (d) demonstrates the thickened, deformed appearance of the metaphyseal bone collar in relationship to the metaphysis and cortex

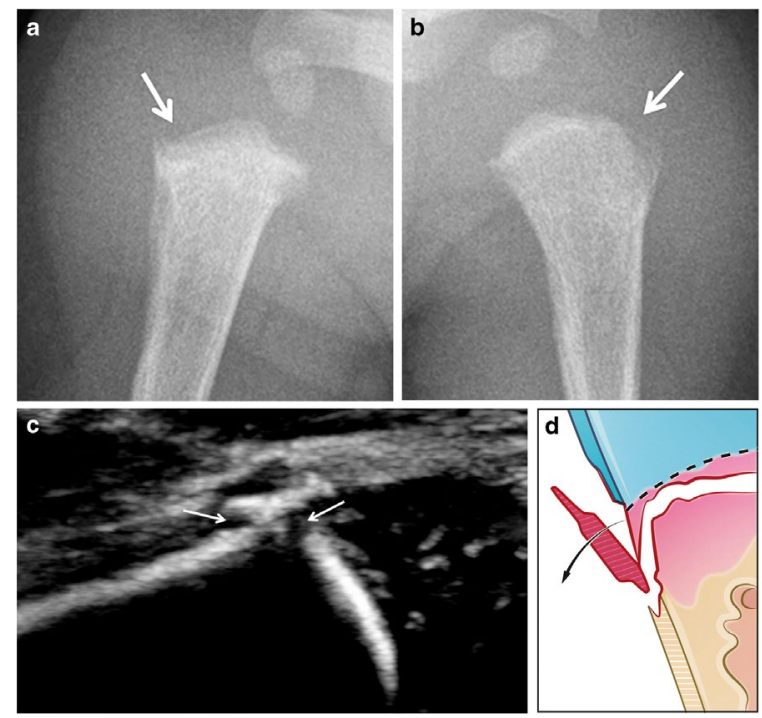


Fig 4. Anteroposterior and lateral radiographs of a 2-month-old girl demonstrate a left proximal humerus metaphyseal bucket handle deformity on radiograph (arrows in a and b), consistent with CML. A longitudinal US image (c) of the anterior proximal humerus metaphysis demonstrates metaphyseal bone collar fracture (arrows), with disruption of the metaphyseal bone collar from the underlying metaphysis. The illustration (d) demonstrates the fracture undermining the metaphyseal bone collar
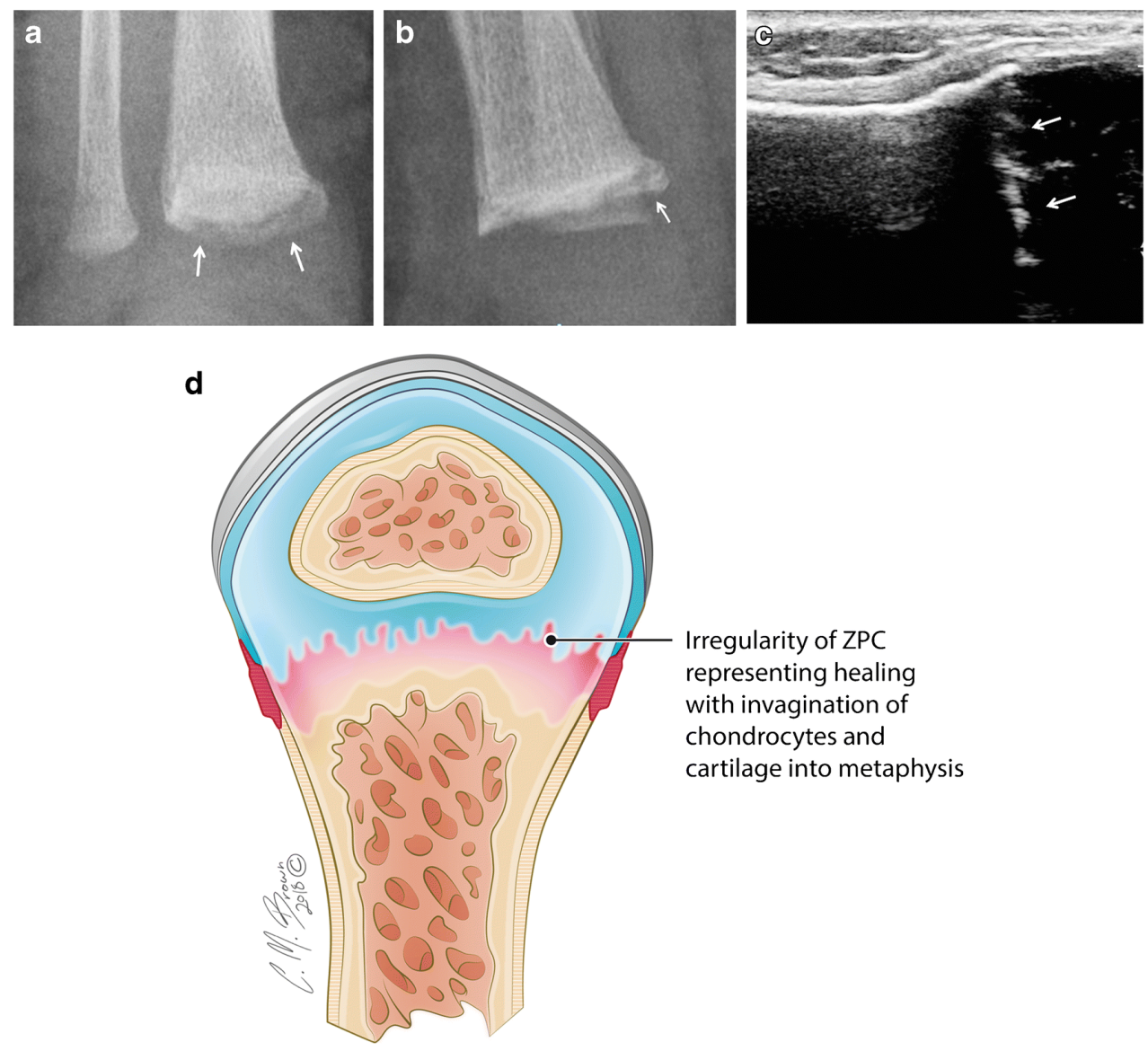

Fig. 5 Anteroposterior and lateral radiographs of a 5-month-old girl demonstrate right distal tibia metaphyseal bucket handle deformity (arrows in a and b), consistent with CML. A longitudinal US image (c) of the medial distal tibia metaphysis demonstrates sonographic zone of provisional calcification (ZPC) irregularity (arrows), with lack of the expected normal single, thin echogenic line. The illustration (d) demonstrates ZPC irregularity with invagination of chondrocytes and non-ossified cartilage into the metaphysis 

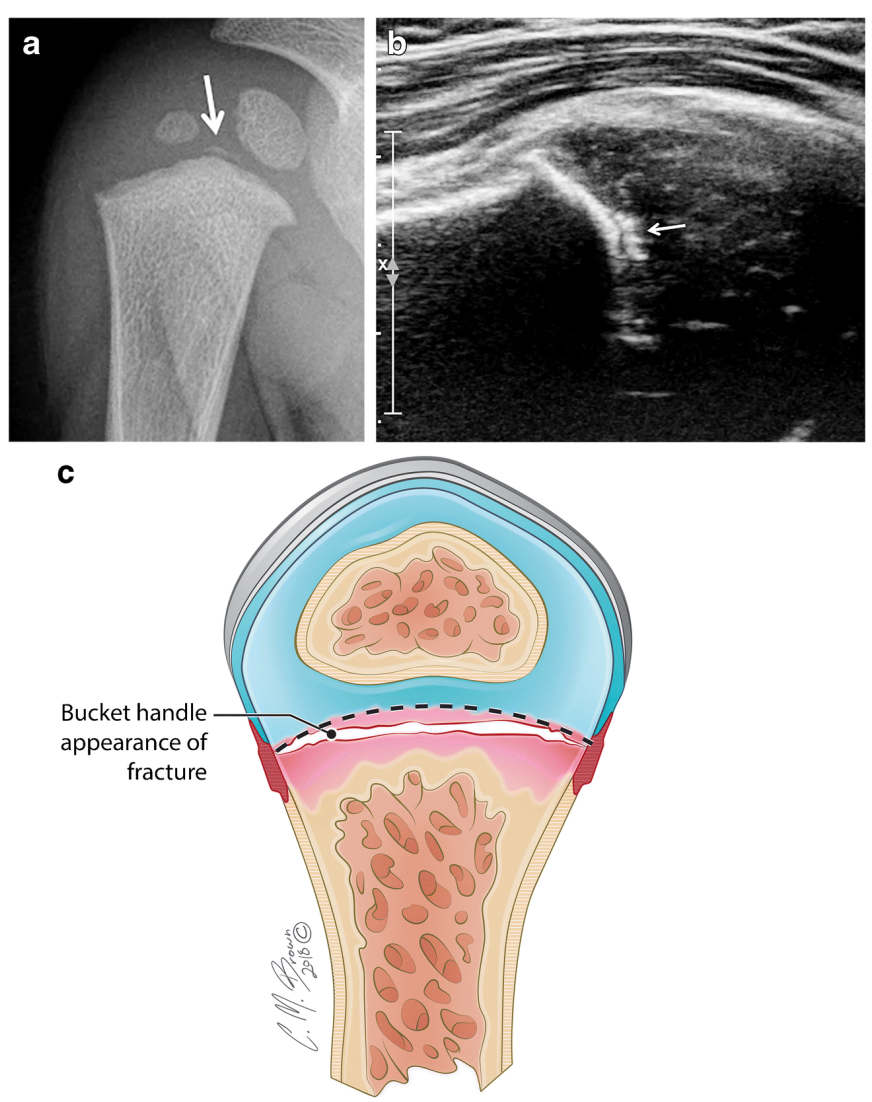

Fig. 6 Anteroposterior radiograph of a 9-month-old boy demonstrates right proximal humerus metaphyseal bucket handle deformity ( $a$, arrow), consistent with CML. Longitudinal US image (b) of the posterior proximal humerus metaphysis demonstrates sonographic zone of provisional calcification with multiple lines visible (arrow), consistent with the ultrasonographic bucket handle appearance. The illustration (c) demonstrates the bucket handle appearance of the fracture

\section{STATISTICAL ANALYSIS}

Descriptive statistics were used to evaluate the number of positive US studies, the type of metaphyseal bone collar and sonographic zone of provisional calcification abnormalities, and the views in which the US abnormalities were identified. 


\section{RESULTS}

\section{PATIENT POPULATION}

There were 42 patients evaluated for 61 CMLs. We excluded 22 studies in 20 patients as the radiographs did not demonstrate definite CMLs. The final study group comprised $39 \mathrm{CMLs}$ in 22 patients (13 female; mean age: 4.2 months, range: 1-16 months). Of the 22 patients, 6 were from the consent group and 16 were from the group in which there was a clinical indication for the US. CMLs were seen in the tibia $(n=22)$, femur $(n=11)$, humerus $(n=3)$, radius $(n=2)$ and fibula $(n=1)($ Table 1$)$.

\begin{tabular}{|l|l|l|l|l|l|l|l|}
\hline & $\begin{array}{l}\text { Distal } \\
\text { femur }\end{array}$ & $\begin{array}{l}\text { Proximal } \\
\text { tibia }\end{array}$ & $\begin{array}{l}\text { Proximal } \\
\text { fibula }\end{array}$ & $\begin{array}{l}\text { Distal } \\
\text { tibia }\end{array}$ & $\begin{array}{l}\text { Proximal } \\
\text { humerus }\end{array}$ & $\begin{array}{l}\text { Distal } \\
\text { humerus }\end{array}$ & $\begin{array}{l}\text { Distal } \\
\text { radius }\end{array}$ \\
\hline Right & 5 & 5 & 1 & 8 & 1 & 0 & 1 \\
\hline Left & 6 & 5 & 0 & 4 & 1 & 1 & 1 \\
\hline $\begin{array}{l}\text { Total } \\
(n=39)\end{array}$ & 11 & 10 & 1 & 12 & 2 & 1 & 2 \\
\hline
\end{tabular}

\section{ULTRASOUND FINDINGS}

Thirty-three of the 39 (85\%) CMLs had positive US findings, while 6 (15\%) US studies were normal (false negative).

\section{METAPHYSEAL BONE COLLAR}

The most common findings were metaphyseal bone collar thickening, seen in 30 of 39 CMLs (77\%) and deformity, seen in 29 (74\%). Fracture of the metaphyseal bone collar was identified in 12 of 39 CMLs (31\%) (Table 2).

\section{Subperiosteal bone collar}

\begin{tabular}{|l|l|}
\hline Thickening & $30(77 \%)$ \\
\hline Deformity & $29(74 \%)$ \\
\hline Fracture & $12(31 \%)$ \\
\hline
\end{tabular}




\section{Sonographic zone of provisional calcification}

\begin{tabular}{|l|l|}
\hline Irregularity & $16(41 \%)$ \\
\hline Multiple lines & $5(13 \%)$ \\
\hline
\end{tabular}

\section{SONOGRAPHIC ZONE OF PROVISIONAL CALCIFICATION}

Irregularity was seen in 16 of $39(41 \%)$ CMLs. Five of the 39 CMLs (13\%) had multiple lines in the epiphysis parallel to the sonographic zone of provisional calcification, with a pattern suggestive of the bucket handle fracture seen on radiography (Table 2).

\section{LOCATION OF ABNORMAL US FINDINGS}

Four of the CMLs had only three of four documented views obtained and one CML had only two of four views. Of the $34 \mathrm{CMLs}$ in which all 4 US views were obtained, in only 2 (both distal tibia), were abnormal findings seen on all US views (anterior, medial, lateral and posterior). Of the remaining $32 \mathrm{CMLs}$, abnormalities were identified in 3 of 4 views $(n=9), 2$ of 4 views $(n=13)$ and 1 of 4 views $(n=10)$. Most abnormalities were identified in the lateral $(n=22)$ and medial $(n=21)$ views. In 6 of the 10 distal tibia CMLs $(60 \%)$, the abnormality was most commonly seen at the medial aspect.

\section{FALSE NEGATIVES}

Three of the six false-negative US studies were in the same patient and included CMLs of the right distal femur, right proximal tibia and left proximal tibia. The remaining three false negatives included two left proximal tibia CMLs and one right distal radius CML (Fig. 7).
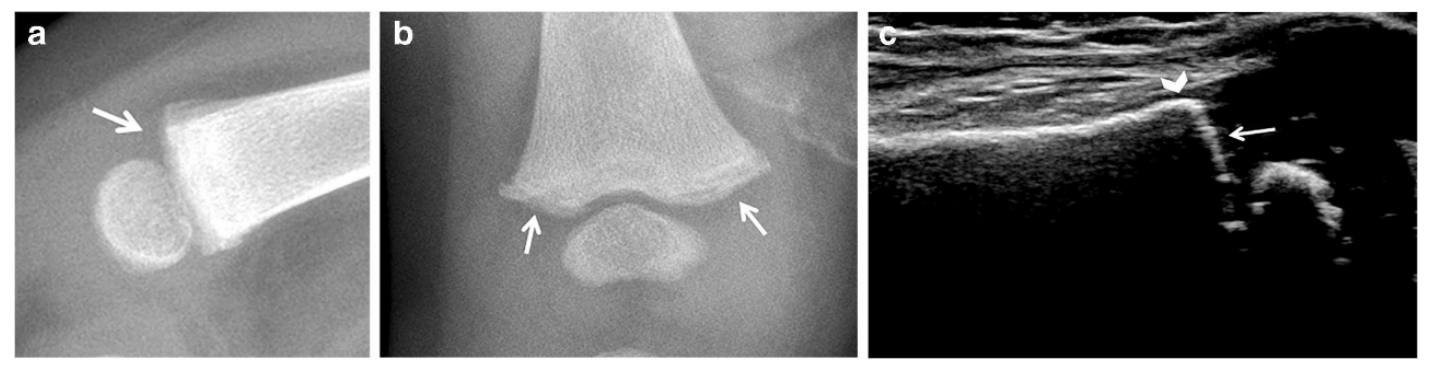

Fig. 7 Anteroposterior and lateral radiographs of a 3-month-old girl demonstrate right distal femur submetaphyseal lucency and metaphyseal irregularity (arrows in a and b), 
consistent with CML. A false-negative longitudinal US image (c) of the anterior distal femoral metaphysis shows the normal appearance of the metaphyseal bone collar (arrowhead) and sonographic zone of provisional calcification (arrow)

\section{DISCUSSION}

While CMLs have distinctive radiographic findings, these often can be subtle or occult $[2,3,4]$. There are also metaphyseal variations that occasionally can be difficult to distinguish with certainty from CMLs [5, 6]. Alternative methods, including 18F-NaF PET imaging and whole-body MRI, have not been shown to aid in the specific diagnosis of the CML $[8,9]$.

When there is a subtle finding of the metaphysis that may indicate a CML, currently the main mode of evaluation is a 2-week follow-up skeletal survey for assessing evidence of healing such as subperiosteal new bone formation, increased density at the metaphyseal margin and subphyseal lucencies [18]. However, many CMLs do not heal similarly to long bone fractures $[19,20]$. New literature indicates that only a minority of distal tibia CMLs demonstrate subperiosteal new bone formation with serial radiography [21]. In any event, this method of evaluation requires a 2-week waiting period during which the appropriate disposition of the child may become an enormous challenge, particularly if the CML in question is the only evidence of child abuse.

In 1993, Markowitz et al. [15] presented a pictorial paper on the normal and abnormal US findings of the knee metaphysis. US demonstrated the fine details of the immature bony structure of the metaphysis, including the metaphyseal bone collar, which is involved in the CML $[12,13,14,22]$. This paper demonstrated the potential of US in evaluating CMLs. Aside from the description of US findings of epiphyseal separation [11, 16], to our knowledge no other study has been published on the utility of US in evaluating CMLs.

Markowitz et al. [15] presented three cases of CMLs, all with a fracture in the metaphyseal bone collar. In our study of $39 \mathrm{CMLs}$ diagnosed with radiography, we found that US was positive in 33 of the 39 cases $(85 \%)$. The most common abnormalities were thickening $(30 / 39,77 \%)$ or deformity $(29 / 39,74 \%)$ of the metaphyseal bone collar. A 
fracture of the metaphyseal bone collar was seen in 12 of 39 CMLs (31\%). This coincides with the most recent descriptions of the histopathology of the $\mathrm{CML}$, as a fracture extending in a planar fashion through the metaphysis and undercutting the metaphyseal bone collar $[13,22]$.

Abnormalities in the sonographic zone of provisional calcification were less common. Irregularities were seen in less than half of the CMLs $(16 / 39,41 \%)$. The irregularity may relate to the healing phase of $\mathrm{CML}$ and may correlate with previously described radiographic findings of healing with invagination of chondrocytes and cartilage into the metaphysis $[19,20]$. Few $(5 / 39,13 \%)$ had the appearance of multiple lines at the sonographic zone of provisional calcification, similar to the bucket handle appearance on radiography.

Similar to radiographic findings, abnormal US findings of definite CMLs were generally not seen in all views of the metaphysis; thus, all sides of the metaphysis should be evaluated [22]. In most cases, abnormalities were seen in only one or two views of the metaphysis. Only two patients had abnormalities seen in all four US views of the metaphysis.

It is of interest that in the distal tibia CMLs, the medial aspect was the most common site of abnormality. This is consistent with a recently published paper demonstrating that radiographic abnormalities are more commonly seen at the medial aspect of the distal tibia, likely due to valgus or varus traction [22].

Six false-negative US studies importantly indicate that a negative US does not exclude the diagnosis of a CML.

There are limitations to this study. Inherently, there is no pathology available as a gold standard in the diagnosis of the CMLs and all of the US findings were based on subjective assessment that limits a definition of pathology. Additionally, as the radiologists reviewed the US studies in consensus, there is no information on interobserver variability. The review was done in correlation with radiographs and the reviewers knew that there was a CML diagnosed on radiography. This may bias for overdiagnosis of CMLs by US and evaluation for US accuracy is thus significantly limited, particularly without blinding 
the radiographs. However, the purpose of this study was not to evaluate the accuracy of US, but to identify US findings that can be associated with CMLs.

\section{CONCLUSION}

In summary, in $85 \%$ of studies with a radiographic diagnosis of CML, US was abnormal. Most cases had thickening and/or deformity of the metaphyseal bone collar; an actual fracture line was only observed in one-third of the cases. Abnormalities seen in the sonographic zone of provisional calcification were less common. While a negative US does not exclude CML, we conclude that US may have a role in either confirming or evaluating radiographically equivocal CMLs. A future study is necessary to better establish the accuracy of US in the diagnosis of CMLs, including interobserver variability, when viewed by radiologists blinded to skeletal survey and clinical information.

\section{REFERENCES}

1. Wootton-Gorges, S. L., Soares, B. P., Alazraki, A. L., Anupindi, S. A., Blount, J. P., Booth, T. N., Dempsey, M. E., Falcone, R. A., Hayes, L. L., Kulkarni, A. V., Partap, S., Rigsby, C. K., Ryan, M. E., Safdar, N. M., Trout, A. T., Widmann, R. F., Karmazyn, B. K., \& Palasis, S. (2017). ACR Appropriateness Criteria® Suspected Physical AbuseChild. Journal of the American College of Radiology, 14(5, Supplement), S338-S349. https://doi.org/10.1016/j.jacr.2017.01.036

2. Caffey, J. (1957). Some Traumatic Lesions in Growing Bones other than Fractures and Dislocations: Clinical and Radiological Features-The Mackenzie Davidson Memorial Lecture. The British Journal of Radiology, 30(353), 225-238. https://doi.org/10.1259/0007-1285-30-353-225

3. Kleinman, P. K., Marks, S. C., Richmond, J. M., \& Blackbourne, B. D. (1995). Inflicted skeletal injury: A postmortem radiologic-histopathologic study in 31 infants. American Journal of Roentgenology, 165(3), 647-650. https://doi.org/10.2214/ajr.165.3.7645487 
4. Kleinman, P. K., Perez-Rossello, J. M., Newton, A. W., Feldman, H. A., \& Kleinman, P. L. (2011). Prevalence of the Classic Metaphyseal Lesion in Infants at Low Versus High Risk for Abuse. American Journal of Roentgenology, 197(4), 1005-1008. https://doi.org/10.2214/AJR.11.6540

5. Kleinman, P. K., Belanger, P. L., Karellas, A., \& Spevak, M. R. (1991). Normal metaphyseal radiologic variants not to be confused with findings of infant abuse. American Journal of Roentgenology, 156(4), 781-783. https://doi.org/10.2214/ajr.156.4.2003446

6. Kleinman, P. K., Sarwar, Z. U., Newton, A. W., Perez-Rossello, J. M., Rebello, G., \& Herliczek, T. W. (2009). Metaphyseal Fragmentation with Physiologic Bowing: A Finding Not to Be Confused with the Classic Metaphyseal Lesion. American Journal of Roentgenology, 192(5), 1266-1268. https://doi.org/10.2214/AJR.08.1619

7. Jenny, C., Hymel, K. P., Ritzen, A., Reinert, S. E., \& Hay, T. C. (1999). Analysis of Missed Cases of Abusive Head Trauma. JAMA, 281(7), 621-626. https://doi.org/10.1001/jama.281.7.621

8. Perez-Rossello, J. M., Connolly, S. A., Newton, A. W., Zou, K. H., \& Kleinman, P. K. (2010). Whole-Body MRI in Suspected Infant Abuse. American Journal of Roentgenology, 195(3), 744-750. https://doi.org/10.2214/AJR.09.3364

9. Drubach, L. A., Johnston, P. R., Newton, A. W., Perez-Rossello, J. M., Grant, F. D., \& Kleinman, P. K. (2010). Skeletal Trauma in Child Abuse: Detection with 18F-NaF PET. Radiology, 255(1), 173-181. https://doi.org/10.1148/radiol.09091368 
10. Oestreich, A. E., \& Ahmad, B. S. (1992). The periphysis and its effect on the metaphysis: I. Definition and normal radiographic pattern. Skeletal Radiology, 21(5), 283-286. https://doi.org/10.1007/BF00241764

11. Kleinman PK (2015) Lower extremity trauma; upper extremity trauma. In: Kleinman P (ed) Diagnostic imaging of child abuse, 3rd edn. St. Louis, MO: Mosby-Year Book

12. Kleinman, P., Marks, S., \& Blackbourne, B. (1986). The metaphyseal lesion in abused infants: A radiologic-histopathologic study. American Journal of Roentgenology, 146(5), 895-905. https://doi.org/10.2214/ajr.146.5.895

13. Kleinman, P. K., \& Marks, S. C. (1995). Relationship of the subperiosteal bone collar to metaphyseal lesions in abused infants. Journal of Bone and Joint Surgery: American Volume, 77(10), 1471-1476.

14.Tsai, A., Coats, B., \& Kleinman, P. K. (2017). Biomechanics of the classic metaphyseal lesion: Finite element analysis. Pediatric Radiology, 47(12), 1622-1630. https://doi.org/10.1007/s00247-017-3921-y

15. Markowitz, R. I., Hubbard, A. M., Harty, M. P., Bellah, R. D., Kessler, A., \& Meyer, J. S. (1993). Sonography of the knee in normal and abused infants. Pediatric Radiology, 23(4), 264-267. https://doi.org/10.1007/BF02010912

16. Supakul, N., Hicks, R. A., Caltoum, C. B., \& Karmazyn, B. (2015). Distal Humeral Epiphyseal Separation in Young Children: An Often-Missed Fracture-Radiographic Signs and Ultrasound Confirmatory Diagnosis. American Journal of Roentgenology, 204(2), W192-W198. https://doi.org/10.2214/AJR.14.12788

17. Karmazyn, B., Duhn, R. D., Jennings, S. G., Wanner, M. R., Tahir, B., Hibbard, R., \& Hicks, R. (2012). Long bone fracture detection in suspected child abuse: Contribution 
of lateral views. Pediatric Radiology, 42(4), 463-469. https://doi.org/10.1007/s00247$\underline{011-2248-3}$

18. Kleinman, P. K., Nimkin, K., Spevak, M. R., Rayder, S. M., Madansky, D. L., Shelton, Y. A., \& Patterson, M. M. (1996). Follow-up skeletal surveys in suspected child abuse. American Journal of Roentgenology, 167(4), 893-896. https://doi.org/10.2214/ajr.167.4.8819377

19. Kleinman, P. K., Marks, S. C., Spevak, M. R., Belanger, P. L., \& Richmond, J. M. (1991). Extension of growth-plate cartilage into the metaphysis: A sign of healing fracture in abused infants. American Journal of Roentgenology, 156(4), 775-779. https://doi.org/10.2214/ajr.156.4.2003445

20. Osier, L. K., Marks, S. C., \& Kleinman, P. K. (1993). Metaphyseal extensions of hypertrophied chondrocytes in abused infants indicate healing fractures. Journal of Pediatric Orthopedics, 13(2), 249-254.

21. Tsai A, Kleinman PK (2018) How often is subperiosteal new bone formation noted with the distal tibia classic metaphyseal lesion? Pediatr Radiol 48:S94-S95

22. Tsai, A., Johnston, P. R., Perez-Rossello, J. M., Breen, M. A., \& Kleinman, P. K. (2018). The distal tibial classic metaphyseal lesion: Medial versus lateral cortical injury. Pediatric Radiology, 48(7), 973-978. https://doi.org/10.1007/s00247-018$\underline{4103-2}$ 